\title{
LuxS: its role in central metabolism and the in vitro synthesis of 4-hydroxy-5-methyl-3(2H)- furanone
}

1 Institute of Infections and Immunity, University of Nottingham, Queen's Medical Centre, Nottingham NG7 2UH, UK

2 School of Pharmaceutical Sciences, University of Nottingham, University Park, Nottingham NG7 2RD, UK

3 School of Biosciences, University of Nottingham, Sutton Bonington Campus, Loughborough LE12 5RD, UK

4 Immunology Research, R\&D 21, VA Medical Center, Portland, OR 97201, USA

\author{
Klaus Winzer, ${ }^{1}$ Kim R. Hardie, ${ }^{1,2}$ Nicola Burgess, ${ }^{1}$ Neil Doherty, ${ }^{1}$ \\ David Kirke, ${ }^{2}$ Matthew T. G. Holden, ${ }^{1,2}+$ Rob Linforth, ${ }^{3}$ \\ Kenneth A. Cornell, ${ }^{4}$ Andrew J. Taylor, ${ }^{3}$ Philip J. Hill ${ }^{1,3}$ \\ and Paul Williams ${ }^{1,2}$
}

Author for correspondence: Klaus Winzer. Tel: +44 1159709907 . Fax: +44 1159709923. e-mail: Klaus.Winzer@nottingham.ac.uk

\begin{abstract}
Many bacteria produce extracellular molecules which function in cell-to-cell communication. One of these molecules, autoinducer 2 (AI-2), was first described as an extracellular signal produced by Vibrio harveyi to control luciferase expression. Subsequently, a number of bacteria have been shown to possess Al-2 activity in their culture supernatants, and bear the luxS gene product, which is required for AI-2 synthesis. In Porphyromonas gingivalis, luxS and $p f s$, encoding a 5 '-methylthioadenosine/S-adenosylhomocysteine nucleosidase (MTA/SAH'ase), form an operon, suggesting that $S$ adenosylhomocysteine (SAH) or 5'-methylthioadenosine (MTA) serves as a substrate for Al-2 production. Cell-free extracts of Escherichia coli MG1655, but not DH5 $\alpha$ (which carries a luxS frame-shift mutation) were capable of generating AI-2 activity upon addition of SAH, but not MTA. S-Ribosylhomocysteine (RH) derived from SAH also served as a substrate in $E$. coli MG1655 extracts. RH-supplemented cell-free extracts of Pseudomonas aeruginosa, a bacterium that lacks luxS, only generated Al-2 activity following the introduction of a plasmid containing the Por. gingivalis pfs-luxS operon. In addition, defined in vitro systems consisting of the purified LuxS proteins from Por. gingivalis, E. coli, Neisseria meningitidis or Staphylococcus aureus converted RH to homocysteine and a compound that exhibits Al-2 activity. 4-Hydroxy-5-methyl-3(2H)-furanone was identified by mass spectrometry analysis as a major product formed in this in vitro reaction. In E. coli MG1655, expression of T3SH [the bacteriophage T3 S-adenosylmethionine (SAM) hydrolase] significantly reduced AI-2 activity in culture supernatants, suggesting that AI-2 production is limited by the amount of SAH produced in SAM-dependent transmethylase reactions. The authors suggest that the LuxS protein has an important metabolic function in the recycling of SAH. They also show that $P$ s. aeruginosa is capable of removing Al-2 activity, implying that this molecule may act as a nutrient. In many bacteria Al-2 may in fact represent not a signal molecule but a metabolite which is released early and metabolized in the later stages of growth.
\end{abstract}

Keywords: AI-2, S-adenosylhomocysteine, $S$-ribosylhomocysteine, $S$-ribosylhomocysteine-cleavage enzyme, quorum sensing

†Present address: The Sanger Centre, Wellcome Trust Genome Campus, Hinxton, Cambridge CB10 1SA, UK.

Abbreviations: Al-2, autoinducer-2; DMHF, 2,5-dimethyl-4-hydroxy-3(2H)-furanone; MTA, 5'-methylthioadenosine; MTA/SAH'ase, 5'-methylthioadenosine/S-adenosylhomocysteine nucleosidase; MHF, 4-hydroxy-5-methyl-3(2H)-furanone; RH, S-ribosylhomocysteine; RLSS, rat liver S-adenosylmethionine synthetase; SAM, S-adenosylmethionine; SAH, S-adenosylhomocysteine; T3SH, bacteriophage T3 SAM hydrolase. 


\section{INTRODUCTION}

Many bacteria have evolved signalling systems that allow gene expression to be coordinated in a multicellular fashion. Production of signal molecules, also called 'autoinducers', enables individual cells to sense when the minimal number of bacteria has been achieved for a concerted response to be initiated ('quorum sensing'). Quorum-sensing-controlled multicellular behaviour includes a variety of physiological and morphological processes, e.g. bioluminescence, antibiotic biosynthesis, biofilm differentiation, plasmid conjugal transfer, competence for DNA uptake, sporulation, and the production of virulence determinants in animal, fish and plant pathogens (for reviews see Bassler, 1999; Greenberg, 1999; Williams et al., 2000; Withers et al. 2001).

Several chemically distinct families of autoinducers have been identified. N-Acyl-L-homoserine lactones (AHLs) are exclusively produced by Gram-negative bacteria, usually employing enzymes belonging to the LuxI protein family. Acylated acyl carrier protein (acyl-ACP) or acyl-CoA provides the acyl chain of AHLs while $S$ adenosylmethionine (SAM) provides the homoserine lactone moiety (Moré et al., 1996; Jiang et al., 1998). AHL molecules accumulate during the growth of a bacterial population and activate transcriptional regulators of the LuxR family once a critical concentration has been reached. Besides their role as signal molecules, some AHLs may also act as virulence factors (Telford $e t$ al., 1998; Gardiner et al., 2001).

In contrast, many Gram-positive bacteria employ posttranslationally modified peptides as signal molecules. These peptides, which are created from larger precursors, are usually secreted via ATP-binding cassette (ABC) transporters. Some of these peptides interact with membrane-bound sensor kinases that transduce a signal across the membrane; others are transported into the cell by oligopeptide permeases, where they then interact with intracellular receptors (for reviews see Kleerebezem et al., 1997; Lazazzera \& Grossman, 1998; Novick, 1999; Novick \& Muir, 1999).

Recently, a new family of autoinducer synthases has been described which is present in both Gram-negative and Gram-positive bacteria (Surette et al., 1999). In Vibrio harveyi, the LuxS protein is required for the production of a signal molecule of unknown structure, autoinducer 2 (AI-2), which exerts its activity via a complex phospho-relay system. AI-2 activity has been discovered in spent culture supernatants of many organisms, including Escherichia coli, Helicobacter pylori, Neisseria meningitidis, Porphyromonas gingivalis, Streptococcus pyogenes, Shigella flexneri and Salmonella typhimurium (Bassler et al., 1997; Surette \& Bassler, 1998; Sperandio et al., 1999; Forsyth \& Cover, 2000; Joyce et al., 2000; Burgess et al., 2002; Day \& Maurelli, 2001; Lyon et al., 2001; Winzer et al., 2002). Furthermore, highly conserved LuxS homologues have been identified in a large number of pathogenic and nonpathogenic bacteria by database analysis (Surette et al.,
1999; Bassler, 1999). However, little is known about the regulation of AI-2 production or turnover. Some bacteria, e.g. Sal. typhimurium and E. coli, produce extracellular AI-2 during early exponential growth, but later apparently degrade the autoinducer in the absence of glucose (Surette \& Bassler, 1998, 1999). In the presence of glucose, AI-2 activity remains in the culture supernatant, suggesting that degradation is subject to catabolite repression. AI-2 levels have also been shown to be affected by environmental parameters like osmolarity and $\mathrm{pH}$ (Surette \& Bassler, 1999). In chemostat experiments, pulses of glucose, iron or $\mathrm{NaCl}$ induced the up-regulation of AI-2 production by E. coli K-12, whereas others, e.g. heat shock, ethanol or $\mathrm{H}_{2} \mathrm{O}_{2}$, decreased AI-2 activity (DeLisa et al., 2001a). These data suggest that AI-2 production and degradation are tightly linked with the physiological and metabolic state of the cells.

The discoveries outlined above led to the suggestion that AI-2 may be employed for interspecies communication (Bassler, 1999). However, apart from bioluminescence in $V$. harveyi, no obvious phenotype has been associated with the extracellular accumulation of this molecule in other bacteria, despite the fact that $\operatorname{lu} x S$ mutants have been constructed in E. coli, H. pylori, N. meningitidis, Por. gingivalis, Sal. typhimurium, Sh. flexneri and Strep. pyogenes (Sperandio et al., 1999; Forsyth \& Cover, 2000; Joyce et al., 2000; Burgess et al., 2002; Day \& Maurelli, 2001; Lyon et al., 2001; Winzer et al., 2002). Although a DNA-microarray-based approach suggested that several hundred genes were up- or down-regulated in an E. coli O157: $\mathrm{H} 7 \operatorname{lu} x \mathrm{~S}$ mutant (Spernandio et al., 2001), these changes have not yet been linked to a lack of AI-2 activity, and may in fact be explained by additional functions of the $\operatorname{luxS}$ gene product. Similarly, the significant transcriptional changes observed with an $E$. coli luxS mutant after the addition of conditioned medium from wild-type cultures (DeLisa et al., 2001b) may result from molecules different from AI-2. So far, a signal-transduction pathway responding to AI-2 has only been identified in $V$. harveyi, and genome analysis has not revealed homologous pathways in unrelated species. This raises the question whether AI-2 is indeed a general signal molecule used by many bacteria. If this is the case, then phenotypes abolished in luxS mutants should be restored by exogenous AI-2. Therefore, we sought to investigate the biosynthesis and chemical nature of AI-2.

In this paper, we describe the production of AI-2 in vitro from $S$-ribosylhomocysteine and present evidence to suggest that AI-2 is similar in structure to 4-hydroxy-5methyl-3(2H)-furanone. The LuxS protein appears to be identical to the $S$-ribosylhomocysteine cleavage enzyme described by J. A. Duerre \& C. H. Miller more then 30 years ago (Duerre \& Miller, 1966; Miller \& Duerre, 1968). Whilst the current manuscript was in preparation, Schauder et al. (2001) also identified the pathway of AI2 synthesis, and suggested that this pathway is employed by a variety of bacteria to produce AI-2 for intra- and interspecies communication. However, the work pre- 
sented in this study suggests that the AI-2 molecule may not act as a signal molecule for the majority of bacteria, but is the by-product of an important metabolic pathway, which is secreted during exponential growth, and degraded at a later stage.

\section{METHODS}

Bacterial strains, plasmids and media. The bacterial strains and plasmids used in this study are listed in Table 1. E. coli $\mathrm{DH} 5 \alpha$ was used for cloning experiments. E. coli and Pseudomonas aeruginosa were grown at $37^{\circ} \mathrm{C}$ in Luria-Bertani (LB) medium or on LB agar plates. V. harveyi $\mathrm{BB} 170$ was grown at $30^{\circ} \mathrm{C}$ in $\mathrm{LB}$ medium or $\mathrm{AB}$ medium (Greenberg et al., 1979). Where required, kanamycin $\left(50 \mu \mathrm{g} \mathrm{ml}^{-1}\right)$, ampicillin $\left(75 \mu \mathrm{g} \mathrm{ml}^{-1}\right)$ or carbenicillin $200\left(\mu \mathrm{g} \mathrm{ml}^{-1}\right)$ was added for $V$. harveyi, E. coli and Ps. aeruginosa, respectively.

DNA manipulation. DNA was manipulated by standard methods (Sambrook et al., 1989). Restriction enzymes (Promega) were used according to the manufacturer's instructions. For isolation of plasmid DNA from E. coli the Qiagen Mini and Midi kits (Qiagen) were used.

Transformation. Standard methods were used for the preparation of competent cells, and for the electroporation of plasmids into E. coli (Sambrook et al., 1989) and Ps. aeruginosa (Smith \& Iglewski, 1989).

DNA sequencing and sequence analysis. Automated nonradioactive sequencing reactions were carried out using the BigDye terminator cycle sequencing kit in conjunction with a 373A automated sequencer (Perkin Elmer Applied Biosystems). Sequence analysis and database searches were performed with the Genetics Computer Group software packages and the NCBI BLAST server (http://www.ncbi. nlm.nih.gov/). Metabolic pathways were compared using the 'Kyoto Encyclopedia of Genes and Genomes' (http:// star.scl.kyoto-u.ac.jp/kegg/). For sequence comparisons the programs Gap (complete protein sequences) or BESTFIT (for truncated protein sequences) were used.

Preparation of crude extracts and purification of $5^{\prime}$ methylthioadenosine/S-adenosylhomocysteine nucleosidase (MTA/SAH'ase) and LuxS proteins. For the small-scale preparation of cell-free extracts of E. coli and Ps. aeruginosa, cells were washed once with $50 \mathrm{mM}$ Tris/ $\mathrm{HCl}$ buffer, $\mathrm{pH} 7 \cdot 8$. Cells were suspended in the same buffer containing $100 \mu \mathrm{g}$ lysozyme $\mathrm{ml}^{-1}$ and incubated at room temperature for $15 \mathrm{~min}$, prior to cell disruption by sonication. Disrupted cells were then centrifuged $(10000 \mathrm{~g})$ at $4{ }^{\circ} \mathrm{C}$ for $30 \mathrm{~min}$ to remove cell debris. The clear supernatant is referred to as cell-free extract. LuxS of Por. gingivalis was provided as an $\mathrm{N}$-terminal MalE-fusion protein (MalE-LuxS ${ }_{\mathrm{Pg}}$ ) (Burgess et al., 2002). All other proteins contained N-terminal His-tag fusions. MTA/SAH'ase from $E$. coli (Cornell \& Riscoe, 1998) was overproduced using pProEX HT (Life Technologies) as an expression vector (K. A. Cornell, unpublished). The $\operatorname{luxS}$ genes of E. coli MG1655 [amplified with primers LuxSECF $\left(5^{\prime}\right.$-TTTACCATGGCAATGCCGTTGTTAGATAGC- $\left.3^{\prime}\right)$ and LuxSECR (5'-TAGTCTCGAGACTAGATGTGCAGTTCCTGC- $\left.3^{\prime}\right)$ ] and $N$. meningitidis MC58 [amplified with primers LuxSNMF (5'-TTTACCATGGCAATGCCCCTACTAGACAGTTTC-3') and LuxSNMR (5'-TTTTCTCGAGTTAGGCGTTCAGCAGCCCTTC-3')] were cloned into the NcoI/Xhol sites of pProEX HT (Life Technologies) to create pProEx-lux $S_{\mathrm{Ec}}$ and pProEx$\operatorname{lu} x S_{\mathrm{Nm}}$, respectively. MTA/SAH'ase, MalE-LuxS $S_{\mathrm{Pg}}, \mathrm{LuxS}_{\mathrm{Ec}}$ and $\mathrm{LuxS}_{\mathrm{Nm}}$ were overproduced in E. coli $\mathrm{DH} 5 \alpha$, to avoid contamination with the native E. coli LuxS protein. The Staphylococcus aureus RN6390B luxS gene [amplified with primers LuxSSAF (5'-AATGCTCGAGATGAATGTTGAAAGTTTTAATTTAG-3') and LuxSSAR (5'-TTAACTCGAGTGACTAAGATTTATTTTCCTGTACCG-3')] was cloned into the Xhol site of pET19b (Novagen) to create pET19-lux $S_{\mathrm{Sa}}$ and overexpressed in E. coli BL21 DE3. For large-scale purification, cells were harvested from $100 \mathrm{ml}$

Table 1. Bacterial strains and plasmids used in this study

\begin{tabular}{|c|c|c|}
\hline Strain or plasmid & Relevant genotype/phenotype & Reference \\
\hline \multicolumn{3}{|l|}{ Strains } \\
\hline Ps. aeruginosa $\mathrm{PAO} 1$ & Wild-type strain & Holloway collection \\
\hline E. coli $\mathrm{DH} 5 \alpha$ & $\begin{array}{l}\text { recA1 supE44 endA1 hsdR17 gyrA96 relA1 thi } \Delta\left(\text { lac-proAB) } \mathrm{F}^{\prime}[\text { traD36 }\right. \\
\left.\text { proAB } \text { lacl }^{q} \text { lacZ } \Delta \mathrm{M} 15\right]\end{array}$ & Yanisch-Perron et al. (1985) \\
\hline E. coli MG1655 & Prototrophic E. coli $\mathrm{K}-12, \mathrm{~F}^{-} \lambda^{-} r p h$ & ATCC 47076 \\
\hline V. harveyi $\mathrm{BB} 170$ & AI-1 sensor negative/AI-2 sensor positive & Bassler et al. (1997) \\
\hline \multicolumn{3}{|l|}{ Plasmids } \\
\hline pUCP18 & As pUC18, but additional $1.8 \mathrm{~kb}$ stabilizing fragment for maintenance & Schweizer (1991) \\
\hline pUCP18pfs-lux $S_{\mathrm{Pg}}$ & pUCP18 containing the Por. gingivalis $p f s-l u x S$ operon & This study \\
\hline pProEX HT & Prokaryotic protein expression vector & Life Technologies \\
\hline pProEX HTmtan & pProEX HT containing the $p f s$ gene of E. coli & K. A. Cornell, unpublished \\
\hline pProEx-lux $S_{\mathrm{Ec}}$ & pProEX HT containing the $\operatorname{luxS}$ gene of E. coli MG1655 & This study \\
\hline pProEx-lux $S_{\mathrm{Nm}}$ & pProEX HT containing the $\operatorname{lu} x S$ gene of $N$. meningitidis MC58 & This study \\
\hline pET19b & Prokaryotic protein expression vector & Novagen \\
\hline pET19b-lux $S_{\mathrm{Sa}}$ & pET19b containing the $l u x S$ gene of Staph. aureus RN6390B & This study \\
\hline $\mathrm{pNB} 3$ & $\begin{array}{l}\text { A } 545 \text { bp fragment containing luxS of Por. gingivalis ligated into pMal-c2 } \\
\text { (New England Biolabs) }\end{array}$ & Burgess et al. (2002) \\
\hline pBAD24 & Contains arabinose-inducible $p B A D$ promoter & Guzman et al. (1995) \\
\hline pBAD-RLSS & RLSS cDNA in pBAD24 & Posnick \& Samson (1999) \\
\hline pBAD-T3SAH & T3SH gene in pBAD24 & Posnick \& Samson (1999) \\
\hline
\end{tabular}


cultures grown in LB medium and lysed using BugBuster protein extraction reagent (Novagen) according to the manufacturer's instructions. The soluble His-tagged proteins were purified using the NTA-purification kit from Novagen.

Production of Al-2 in vitro. If not stated otherwise, $2 \mathrm{mM}$ $S$-adenosylhomocysteine (SAH, purchased from Sigma) in $50 \mathrm{mM}$ Tris $/ \mathrm{HCl}$ buffer, $\mathrm{pH} 7 \cdot 8$, was converted enzymically to $S$-ribosylhomocysteine $(\mathrm{RH})$ through incubation with MTA/SAH'ase $\left(100 \mu \mathrm{g} \mathrm{ml}^{-1}\right)$ at $37^{\circ} \mathrm{C}$ for $1 \mathrm{~h}$. This reaction is nearly quantitative and irreversible (Duerre, 1962), and resulted in conversion rates of greater then $98 \%$. The MTA/SAH'ase protein was removed by filtration through Centricon YM-10 or Microcon YM-10 units (Millipore). Subsequently, purified LuxS $\left(500 \mu \mathrm{g} \mathrm{ml}^{-1}\right)$ was added, and the reaction mixture incubated for a further $1-4 \mathrm{~h}$. SAH solutions were bubbled with helium before the addition of enzyme, and the reaction mixtures were incubated in an anaerobic cabinet to prevent oxidation of $\mathrm{RH}$ and the reaction products. AI-2 was also synthesized by incubating $\mathrm{SAH}$ or $\mathrm{RH}$ with cell-free extracts $\left(2.5 \mathrm{mg}\right.$ protein $\left.\mathrm{ml}^{-1}\right)$ prepared from E. coli and Ps. aeruginosa cells. For the partial purification of AI-2 activity, reaction mixtures were dried by rotary evaporation or, alternatively, freeze-dried. AI-2 activity was extracted from the solids of a $5 \mathrm{ml}$ reaction mixture using $0.5 \mathrm{ml}$ methanol.

Analysis of Al-2 production and degradation. AI-2 production was analysed essentially as described by Bassler et al. (1997), using $20 \mu \mathrm{l} \mathrm{AI-2} \mathrm{extract}$ and $180 \mu \mathrm{l}$ 1:5000 diluted overnight cultured $V$. harveyi BB170 in $\mathrm{AB}$ medium. Changes in bioluminescence upon addition of AI- 2 were determined at $30{ }^{\circ} \mathrm{C}$ every $30 \mathrm{~min}$ using a combined, automated luminometer-spectrometer (the Anthos Labtech Lucy1). For quantitative analysis, serial dilutions were performed to determine the AI-2 concentrations which gave half-maximal induction of light production. AI-2 activity was defined as the fold increase in light production in comparison with medium or buffer controls. For a single experiment, the $V$. harveyi bioassay was performed at least in duplicate for each sample. Experiments were repeated at least three times.

Solutions containing AI-2 synthesized in vitro and Ps. aeruginosa culture supernatants were extracted twice with chloroform prior to the analysis of AI-2, which remained in the water phase. This step was introduced to terminate in vitro reactions and to remove toxic compounds (e.g. pyocyanin from $P$ s. aeruginosa assays) which may otherwise interfere with the assay. For AI-2 degradation experiments, $30 \mu \mathrm{l}$ in vitro-synthesized AI-2 was mixed with $90 \mu \mathrm{l}$ washed cells (adjusted to $\mathrm{OD}_{600} 2 \cdot 0$ ) or freshly inoculated cultures and incubated at $37^{\circ} \mathrm{C}$ for $1-4 \mathrm{~h}$. The cell suspensions were then extracted twice with chloroform, and the aqueous phase analysed for AI-2 activity. Furanones tested for AI-2 activity [2,5-dimethyl-4-hydroxy-3(2H)-furanone (DMHF), dihydro2(3H)-furanone, dihydro-5-methyl-2(3H)-furanone, 5-methyl$2(3 H)$-furanone, $2,4(3 H, 5 H)$-furandione, $\alpha$-methyl- $\gamma$-butyrolactone, $(S)$ - $\beta$-hydroxy- $\gamma$-butyrolactone, $2(5 H)$-furanone, $(R)$ $(-)$-dihydro-5-(hydroxymethyl)-2(3H)-furanone and $(S)-(-)$ dihydro-5-(hydroxymethyl)-2(3H)-furanone] were purchased from Fluka, Sigma or Acros Organics. 4-Hydroxy-5methyl-3(2H)-furanone (MHF) was obtained as a free sample from Givaudan.

Analysis of in vitro reactions. Conversion of SAH to $\mathrm{RH}$, and its degradation during the LuxS reaction were monitored by thin-layer chromatography (TLC) as described by Duerre \& Miller (1966). TLC plates were developed in $80 \%(\mathrm{v} / \mathrm{v}) 1-$ propanol or ethanol/water/acetic acid $(65: 34: 1$, by vol.). Ninhydrin $(0 \cdot 2 \%, \mathrm{w} / \mathrm{v})$ in acetone was used for the detection of homocysteine residues. Homocysteine levels in solutions were quantified using Ellman's reagent (Sigma) according to the method described in the thiol and sulfide quantitation kit from Molecular Probes. Fifty microlitres of the reaction mixture was combined with $350 \mu \mathrm{l} 5 \mathrm{mM}$ sodium acetate buffer, $50 \mathrm{mM} \mathrm{NaCl}, 0.5 \mathrm{mM}$ EDTA, $\mathrm{pH} 4 \cdot 7$, and then added to $690 \mu \mathrm{l} 40 \mathrm{mM}$ sodium phosphate buffer, $2 \mathrm{mM}$ EDTA, $\mathrm{pH} 7 \cdot 6$. Ten microlitres of Ellman's reagent [5,5'-dithio-bis(nitrobenzoic acid); $40 \mathrm{mg} \mathrm{ml}^{-1}$ in DMSO] was added and the $A_{412}$ of the mixture was measured, using the molar absorption coefficient for 2-nitro-5-thiobenzoate $\left(13600 \mathrm{M}^{-1} \mathrm{~cm}^{-1}\right)$, which is generated from Ellman's reagent following reaction with the free thiol group of homocysteine. Alternatively, homocysteine was modified using $\mathrm{N}$-ethylmaleimide and then incubated with $3 \mathrm{M} \mathrm{NaOH}$ to yield a pink product, which can be quantified at $520 \mathrm{~nm}$ as described by Duerre \& Miller (1966). The maleimide derivative of homocysteine was also analysed by HPLC in comparison with a commercial homocysteine standard (Sigma). A Genosys AQ $4 \mu$ column (Jones Chromatography) in conjunction with the Photodiode array system 996 (Waters) was employed to separate the compounds present in the reaction mixtures using a gradient of acetonitrile in water. Data were collected and analysed using the Millennium 3.2 software (Waters).

Electrospray MS analysis was used to identify SAH and RH in reaction mixtures. Proteins were removed by filtration through Centricon YM-10 or Microcon YM-10 units (Millipore), and the reaction mixes were diluted 1:1 with methanol and analysed by direct injection. Methanol extracts containing in vitro-synthesized AI-2 were analysed by GC-MS. The GC-MS was operated in full-scan mode and spectra were collected from $m / z 40$ to 200 .

\section{RESULTS}

\section{SAH is a precursor in Al-2 synthesis}

Whilst analysing the function of LuxS in Por. gingivalis, we noticed that in this organism luxS is located directly downstream of a putative $p f_{s}$ homologue, encoding MTA/SAH'ase (Burgess et al., 2002). RT-PCR analysis revealed that $p f s$ and $l u x S$ form an operon, a finding also recently reported by Chung et al. (2001). Whilst the luxS gene could be inactivated, this was not possible for $p f s$, suggesting an essential function (Burgess et al., 2002). Since it was conceivable that $p f s$ is required for AI-2dependent signalling, we were interested to determine whether a similar gene arrangement is present in other bacteria. Analysis of the finished and unfinished genomes of more then 40 bacterial species revealed that in most species, $\operatorname{lu} x S$ is not linked to any specific gene class. However, in two species $\operatorname{luxS}$ is situated adjacent to genes involved in homocysteine and methionine metabolism. In Borrelia burgdorferi, $p f s$ and luxS are located downstream of $m e t K$. Furthermore, in Clostridium difficile, the met $H$ gene is separated from luxS by only one open reading frame. met $H$ and metK encode $N^{5}$-methyltetrahydrofolate-homocysteine methyltransferase and SAM synthetase, respectively. Fig. 1 shows that these enzymes, together with MTA/ SAH'ase, are part of a metabolic cycle, the function of which is the production of the methyl-group donor SAM and the conversion of SAH, the product of SAMdependent transmethylase reactions, back to homo- 


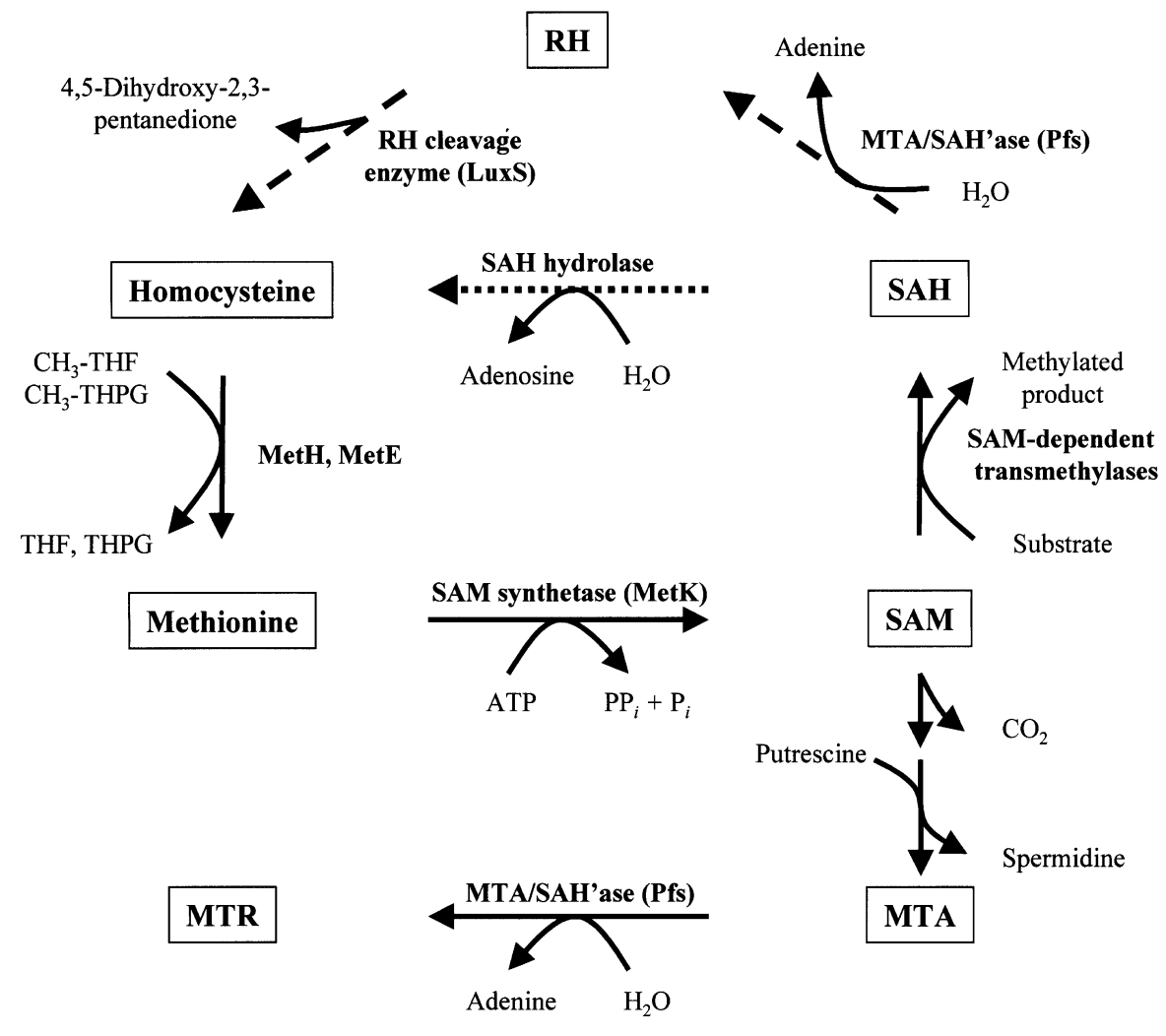

Fig. 1. S-Adenosylmethionine (SAM) metabolism in bacteria. Methionine is converted to SAM in a reaction catalysed by SAM synthetase (methionine adenosyltransferase). In SAM-dependent methyltansferase reactions SAM is converted to Sadenosylhomocysteine (SAH). In some bacteria, e.g. Ps. aeruginosa, SAH hydrolase catalyses the hydrolysis of SAH to homocysteine and adenosine (dotted arrow). Other bacteria, e.g. E. coli, produce homocysteine in two steps, catalysed by methylthioadenosine/SAH nucleosidase (MTA/SAH'ase) and S-ribosylhomocysteine (RH) cleavage enzyme (dashed arrows). Methionine is then recycled from homocysteine. Homocysteine is also formed from oxaloacetate in seven steps as part of the de novo methionine-biosynthesis pathway (not shown). In E. coli, two enzymes catalyse the transfer of the methyl group of $N^{5}$-methyltetrahydropteroryl glutamate $\left(\mathrm{CH}_{3}-\mathrm{THPG}\right)$ to the sulphur of homocysteine to form methionine. One of these, the cobalamin-dependent methionine synthase (MetH) can also use $N^{5}$-methyltetrahydrofolate $\left(\mathrm{CH}_{3}-\mathrm{THF}\right)$ as a methyl donor, whereas the cobalamin-independent methionine synthase (MetE) is restricted to $\mathrm{CH}_{3}-\mathrm{THPG}$. SAM is also involved in the production of polyamines, thereby yielding MTA. MTA is converted to methylthioribose (MTR) and adenine by MTA/SAH'ase, the same enzyme that hydrolyses SAH to RH and adenine. The further metabolism of MTR is not known in E. coli, but in Klebsiella pneumoniae MTR is converted back to methionine. Arrows in the figure indicate the direction of metabolic conversions in vivo. For a review of SAM metabolism see Greene (1996).

cysteine and methionine. However, SAM is also a substrate in polyamine biosynthesis, where it is converted in two steps to methylthioadenosine (MTA). Interestingly, both SAH and MTA are substrates of the MTA/SAH'ase, suggesting that either may serve as a precursor in AI-2 synthesis.

To test this hypothesis, MTA and SAH were added to cell-free extracts of E. coli MG1655, E. coli DH5 $\alpha$ (which contains a luxS frame-shift mutation; Surette et al., 1999) and E. coli DH5 $\alpha$ harbouring the Por. gingivalis $p f s-l u x S$ operon [E. coli DH5 $\alpha$ (pUCP18pfslux $\left.S_{\mathrm{Pg}}\right)$ ]. AI-2 production was monitored using the $V$. harveyi bioassay. AI-2 production was only observed for E. coli MG1655 and E. coli DH5 $\alpha\left(\mathrm{pUCP} 18 p f s-l u x S_{\mathrm{Pg}}\right)$ in the presence of SAH, but not MTA (Table 2). This indicated that $\mathrm{SAH}$ is a precursor of AI-2 synthesis, although it may not be the direct substrate of LuxS. Since SAH is converted to $S$-ribosylhomocysteine (RH) and adenine in an irreversible reaction catalysed by
MTA/SAH'ase in E. coli (Fig. 1), these substrates were analysed as well. Using the purified MTA/SAH'ase from E. coli, SAH was almost quantitatively converted to RH and adenine (see Methods) prior to the addition of cell-free extracts and a very similar profile of AI-2 production to that seen with SAH was obtained (Table 2 ). As addition of adenine to crude extracts did not result in AI-2 production, $\mathrm{RH}$ is likely to be the precursor of AI-2 synthesis.

To determine whether only LuxS and MTA/SAH'ase are required to generate AI-2 from SAH, pUCP18pfs$\operatorname{lux} S_{\mathrm{Pg}}$ was introduced into Ps. aeruginosa, a bacterium that does not contain $p f s$ or $\operatorname{lu} x S$ homologues. However, culture supernatants of $P$ s. aeruginosa $\mathrm{PAO}$ (pUCP18pfs$\operatorname{lu} x S_{\mathrm{Pg}}$ ) contained no AI-2 activity and no activity was detected after adding SAH to cell-free extracts (Table 2). As Ps. aeruginosa contains an SAH hydrolase (Fig. 1), $\mathrm{SAH}$ levels may have been too low to sustain production of detectable levels of AI-2. Therefore, enzymically 
Table 2. Al-2 production by cell-free extracts of $E$. coli and Ps. aeruginosa

AI-2 activities for a single experiment are shown, although the experiment was repeated three times with similar results. Replicate assays agreed within $20 \%$. AI-2 activity is compared with background activities (crude extracts without substrate).

\begin{tabular}{|c|c|c|}
\hline Cell-free extract & Substrate $(2 \mathrm{mM})$ & $\begin{array}{l}\text { AI-2 activity (fold } \\
\text { induction) }\end{array}$ \\
\hline \multicolumn{3}{|l|}{ E. coli } \\
\hline MG1655 & SAH & 9500 \\
\hline MG1655 & RH & 13300 \\
\hline MG1655 & MTA & 1 \\
\hline MG1655 & Adenine & 3 \\
\hline DH $5 \alpha$ & SAH & 1 \\
\hline DH $5 \alpha$ & RH & 2 \\
\hline DH5 $\alpha\left(\mathrm{pUCP} 18 p f s-l u x S_{\mathrm{Pg}}\right)$ & SAH & 10400 \\
\hline DH5 $\alpha\left(\mathrm{pUCP} 18 p f s-\operatorname{lu} x S_{\mathrm{Pg}}\right)$ & RH & 11100 \\
\hline DH5 $\alpha\left(\mathrm{pUCP} 18 p f s-l u x S_{\mathrm{Pg}}\right)$ & MTA & 3 \\
\hline $\mathrm{DH} 5 \alpha\left(\mathrm{pUCP} 18 p f s-l u x S_{\mathrm{Pg}}\right)$ & Adenine & 2 \\
\hline \multicolumn{3}{|l|}{ Ps. aeruginosa } \\
\hline $\mathrm{PAO}(\mathrm{pUCP} 18)$ & $\mathrm{SAH}$ & 2 \\
\hline $\mathrm{PAO}(\mathrm{pUCP} 18)$ & RH & 1 \\
\hline $\mathrm{PAO}\left(\mathrm{pUCP} 18 p f_{s}-l u x S_{\mathrm{Pg}}\right)$ & SAH & 9 \\
\hline $\mathrm{PAO}\left(\mathrm{pUCP} 18 p f_{s}-l u x S_{\mathrm{Pg}}\right.$ ) & $\mathrm{RH}$ & 340 \\
\hline
\end{tabular}

prepared RH was added (after the removal of MTA/ SAH'ase) to cell-free extracts of $P$ s. aeruginosa carrying either pUCP18pfs-lux $S_{\mathrm{Pg}}$ or pUCP18. Significant AI-2 activity was detected in cell-free extracts containing the Por. gingivalis LuxS protein (Table 2), suggesting that $\mathrm{RH}$ is the immediate precursor of the LuxS-catalysed reaction.

\section{LuxS converts $\mathrm{RH}$ to $\mathrm{Al}-2$ and homocysteine}

The results obtained with the cell-free extracts suggested that LuxS may be identical to the RH cleavage enzyme described by Miller \& Duerre (1968). Therefore, a defined in vitro assay was developed, using the purified MTA/SAH'ase from E. coli, and the purified LuxS proteins of Por. gingivalis (MalE-LuxS $\mathrm{Pg}_{\mathrm{Pg}}$, a chimeric protein with MalE N-terminally fused to $\operatorname{LuxS}_{\mathrm{Pg}}$ ), N. meningitidis MC58 ( $\mathrm{LuxS}_{\mathrm{Nm}}$ ), Staph. aureus RN6390B $\left(\operatorname{LuxS}_{\mathrm{Sa}}\right)$ or E. coli MG1655 (LuxS $\left.\mathrm{Ec}\right)$. Each enzyme, with the exception of $\operatorname{LuxS}_{\mathrm{Sa}}$, was purified from E. coli $\mathrm{DH} 5 \alpha$ to avoid contamination with $\mathrm{LuxS}_{\mathrm{Ec}}$. SAH was first converted to RH by the addition of MTA/SAH'ase. Both TLC and MS analysis indicated that the conversion to $\mathrm{RH}$ was greater then $98 \%$ (data not shown). The MTA/SAH'ase protein was then removed by filtration, and the resulting RH solution incubated with the LuxS proteins. In control experiments, $\mathrm{RH}$ was replaced by adenine, ribose and MTA. Production of AI-2 activity was only observed in the presence of $\mathrm{RH}$ and a LuxS protein (Table 3), indicating that these are sufficient to produce AI-2 activity.

According to Duerre \& Miller (1966) and Miller \& Duerre (1968), homocysteine is one of the products formed from $\mathrm{RH}$ in a reaction catalysed by the $\mathrm{RH}$ -
Table 3. In vitro production of Al-2

AI-2 activities for a single experiment are shown, although the experiment was repeated three times with similar results. Replicate assays agreed within $22 \%$. AI-2 activity is with background activities (enzyme without substrate).

\begin{tabular}{|c|c|c|}
\hline Enzyme & Substrate $(2 \mathrm{mM})$ & $\begin{array}{c}\text { AI-2 activity } \\
\text { (fold induction) }\end{array}$ \\
\hline MalE-LuxS ${ }_{\mathrm{Pg}}$ & SAH & 4 \\
\hline MalE-LuxS & $\mathrm{RH}$ & 37300 \\
\hline MalE-LuxS & MTA & 2 \\
\hline MalE-LuxS & Adenine & 3 \\
\hline MalE-LuxS $_{\mathrm{Pg}}$ & Ribose & 2 \\
\hline $\operatorname{LuxS}_{\mathrm{Nm}}$ & $\mathrm{SAH}$ & 4 \\
\hline $\operatorname{LuxS}_{\mathrm{Nm}}$ & $\mathrm{RH}$ & 45400 \\
\hline $\operatorname{LuxS}_{\mathrm{Ec}}$ & SAH & 3 \\
\hline $\operatorname{LuxS}_{\mathrm{Ec}}$ & $\mathrm{RH}$ & 11800 \\
\hline $\operatorname{LuxS}_{\mathrm{Sa}}$ & SAH & 4 \\
\hline $\operatorname{LuxS}_{\mathrm{Sa}}$ & RH & 15600 \\
\hline
\end{tabular}

cleavage enzyme. Indeed, a compound reacting with the $\mathrm{SH}$-group-specific Ellman's reagent was formed in all assays in the presence of LuxS. This compound was tentatively identified as homocysteine by comparing HPLC elution profiles of the reaction mixtures and a commercial standard following N-ethylmaleimide modification (data not shown). TLC analysis and electrospray MS analysis (negative mode) indicated that a large quantity of $\mathrm{RH}$ was still present in the reaction mixtures, even after extending the incubation time from 2 to $4 \mathrm{~h}$ (data not shown). Quantification of SH groups 
(a)<smiles>CC1=C(O)C(=O)CO1</smiles>

MHF

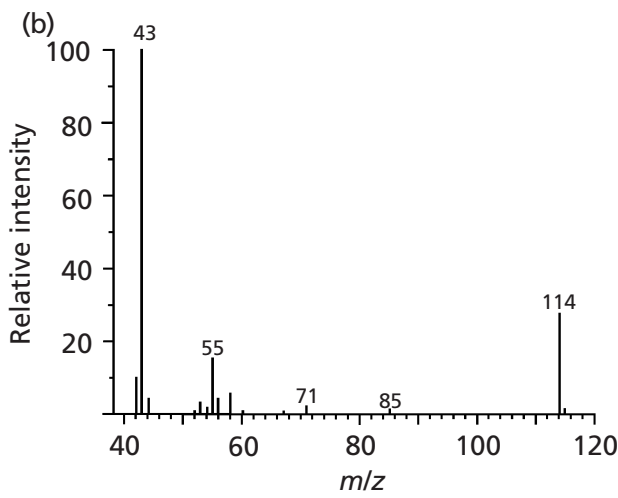

Fig. 2. (a) Chemical structures of 4 -hydroxy-5-methyl-3(2H)furanone (MHF) and 2,5-dimethyl-4-hydroxy-3(2H)-furanone (DMHF); (b) mass spectrum of in vitro-synthesized MHF. The mass spectrum for MHF shows the parent peak at $\mathrm{m} / \mathrm{z} 114$ and characteristic peaks at $m / z 85,71,55$ and 43.

using Ellman's reagent suggested that between $62 \%$ and $68 \%$ of the RH had been converted by MalE-LuxS $\mathrm{Pg}$ and $\operatorname{LuxS}_{\mathrm{Nm}}$ after $2 \mathrm{~h}$ incubation (data not shown).

\section{4-Hydroxy-5-methyl-3(2H)-furanone is a product of the LuxS in vitro reaction}

Apart from homocysteine, 4,5-dihydroxy-2,3-pentanedione has been described as an immediate product of the reaction catalysed by the RH cleavage enzyme (Duerre et al., 1971). However, this compound is very unstable and is probably the precursor of a carbohydrate-like compound described in an earlier publication (Miller \& Duerre, 1968), which derives from the ribose unit of $\mathrm{RH}$. We therefore sought to determine the identity of the carbohydrate-like compound, which may represent AI-2. Preliminary experiments indicated that AI-2 activity from freeze-dried culture supernatants could be extracted by methanol (not shown). Therefore, methanol extracts were prepared from $5 \mathrm{ml}$ reactions after $2 \mathrm{~h}$ incubation, containing $2 \mathrm{mM} \mathrm{RH}$ and either $\operatorname{LuxS}_{\mathrm{Nm}}, \operatorname{LuxS}_{\mathrm{Sa}}$ or MalE-LuxS $\mathrm{Pg}$, at a concentration of $0.5 \mathrm{mg} \mathrm{ml}^{-1}$. The extracts had a fruity-caramel-like odour and contained a substantial amount of AI-2 activity. These were analysed by GC/MS in comparison with extracts from control reactions lacking either the enzymes or the substrate. The GC profiles of reactions and controls revealed only one major difference. This corresponds to a compound with a GC retention time of 15.5 min (eluting from the column just before the $C_{11}$ alkane standard, undecane), and was identified as 4hydroxy-5-methyl-3(2H)-furanone (MHF) by mass spectrometry (Fig. 2), in comparison with the fragmentation pattern for MHF described in the literature (Farine et al., 1993). The same GC retention time and

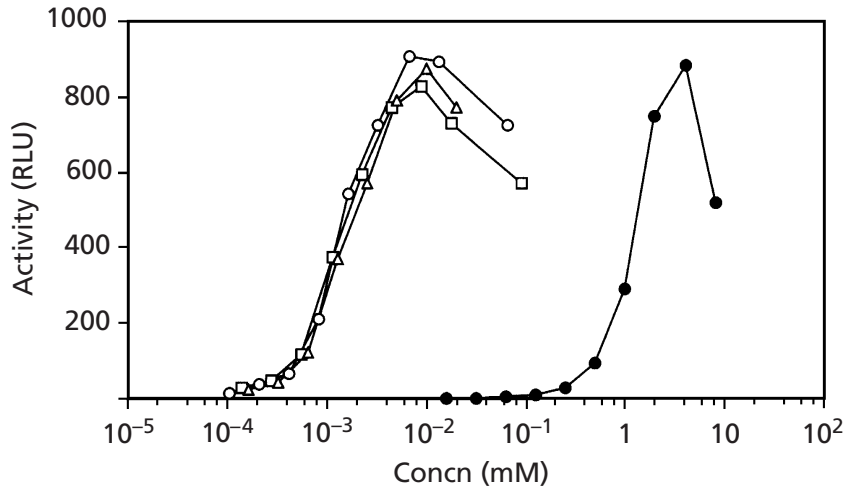

Fig. 3. Activities of in vitro-synthesized Al-2 and synthetic MHF. Al-2 was synthesized in vitro using $10 \mathrm{mM}$ sodium phosphate buffer, pH 7.5, containing $0.5 \mathrm{mg} \mathrm{LuxS}_{\mathrm{Ec}} \mathrm{ml}^{-1}$ and $2 \mathrm{mM} \mathrm{RH}$. The reaction mixture was incubated at $37^{\circ} \mathrm{C}$ and stopped after $15 \mathrm{~min}(\bigcirc), 30 \mathrm{~min}(\square)$ and $60 \mathrm{~min}(\triangle)$. Serial dilutions of these reactions and synthetic MHF $(\bullet)$ were analysed for activity in the $V$. harveyi bioassay. Activity is expressed in relative light units (RLU). The concentration of in vitro-synthesized Al-2 was estimated from the homocysteine levels determined after 15, 30 and $60 \mathrm{~min}$ incubation by assuming a 1:1 ratio. The data shown in this figure represent the mean values of four bioassays; the experiment was repeated three times with similar results.

fragmentation pattern was also observed for a synthetic MHF standard (data not shown). The identification of MHF was not unexpected since this compound was known to be one of products formed in aqueous solutions by the reactive 4,5-dihydroxy-2,3-pentanedione (Nedvidek et al., 1992; Blank \& Fay, 1996).

To establish whether synthetic MHF and in vitrosynthesized AI-2 exhibit identical activities in the $V$. harveyi bioassay, serial dilutions of MHF and AI-2 were analysed (Fig. 3). The concentration of in vitrosynthesized AI-2 was estimated by assuming a 1:1 ratio between homocysteine and AI-2 formation. Synthetic MHF fully activated the bioassay at a concentration of $4 \mathrm{mM}$. Interestingly, half-maximal activation for synthetic MHF was observed at a concentration of approximately $1.1 \mathrm{mM}$, whereas in vitro-synthesized AI-2 showed a comparable activation at a 1000 -fold lower concentration. The results presented in Fig. 3 were obtained using the $\operatorname{LuxS}_{\mathrm{Ec}}$ protein, but half-maximal activation at concentrations between 1 and $3 \mu \mathrm{M}$ were also observed with AI-2 synthesized using $\mathrm{LuxS}_{\mathrm{Sa}}$ and $\mathrm{LuxS}_{\mathrm{Nm}}$. Thus, it appears that MHF, the major product formed in the reaction catalysed by LuxS, is different from AI-2. Incubation of MHF under the conditions described for the in vitro reaction did not increase its activity in the bioassay (data not shown), suggesting that $\mathrm{AI}-2$ is not a degradation product of MHF.

In addition to MHF, various commercially obtainable furanones were tested for AI-2 activity: 2,5-dimethyl4-hydroxy-3(2H)-furanone (DMHF), dihydro-2 $(3 H)$ furanone, dihydro-5-methyl-2 $(3 H)$-furanone, 5-methyl$2(3 H)$-furanone, $2,4(3 H, 5 H)$-furandione, $\alpha$-methyl- $\gamma$ - 
butyrolactone, $(S)$ - $\beta$-hydroxy- $\gamma$-butyrolactone, $2(5 H)$ furanone, $(R)-(-)$-dihydro-5-(hydroxymethyl)-2(3H)furanone and (S)-(-)-dihydro-5-(hydroxymethyl)$2(3 H)$-furanone. Apart from MHF, only DMHF (which is structurally very similar to MHF; Fig. 2a) exhibited activity in the $V$. harveyi bioassay, although activation was maximal (90-fold) only at high concentrations (approx. $2 \mathrm{mM}$ ). Therefore, our results suggest that AI2 has a $3(2 H)$-furanone structure and is very similar to MHF.

\section{In vivo manipulation of SAM levels influences AI-2 production}

If LuxS acts primarily as a metabolic enzyme involved in the recycling of SAH, the level of AI-2 in culture supernatants depends on the net flux of metabolites through the methionine-SAM-SAH-homocysteine cycle depicted in Fig. 1. The amount of SAH produced, and thus the amount of $\mathrm{RH}$, will correlate with the number of SAM-dependent methylations carried out by the cells. Thus, it can be predicted that lowering the cellular concentration of SAM will lead to a decrease in $\mathrm{SAH}$ and hence AI-2 levels. To test this hypothesis, culture supernatants of E. coli MG1655 carrying pBAD24, pBAD-T3SH (encoding bacteriophage T3 SAM hydrolase) or pBAD-RLSS (encoding rat liver SAM synthetase, a highly conserved homologue of bacterial SAM synthetases) were analysed for AI-2 production (plasmids gratefully received from L. D. Samson, Massachusetts Institute of Technology). In E. coli, the expression of T3 SAM hydrolase (T3SH) and rat liver SAM synthetase (RLSS) genes using these plasmids has been shown to decrease and increase the SAM pool size, respectively, without having marked effects on cell growth (Posnick \& Samson, 1999). Culture supernatants were taken from cultures growing in LB medium in the absence of glucose after $4 \mathrm{~h}$, and from overnight cultures $(14 \mathrm{~h})$ grown in the presence of $10 \mathrm{mM}$ glucose. These conditions were chosen as glucose represses the $p B A D$ promoter and has been suggested to prevent the loss of AI-2 activity during lateexponential phase (Surette \& Bassler, 1998). To induce the $P B A D$ promoter, $10 \mathrm{mM} \mathrm{L}$-arabinose was added. A significant reduction of AI-2 levels was observed in cultures producing the SAH hydrolase (Fig. 4). In contrast, AI-2 levels in cultures overexpressing RLSS were moderately increased in comparison with the control (pBAD24 vector only).

\section{Al-2 is inactivated by Ps. aeruginosa}

AI-2 and MHF may represent metabolites which are excreted early during growth, but taken up and utilized during a later stage. Bacteria not producing AI-2, such as $P$ s. aeruginosa, may still be capable of inactivating or degrading these compounds. Ps. aeruginosa and E. coli DH $5 \alpha$ (described not to be capable of AI-2 degradation by Surette et al., 1999) were grown for $13 \mathrm{~h}$ in LB medium, then harvested and washed with the same

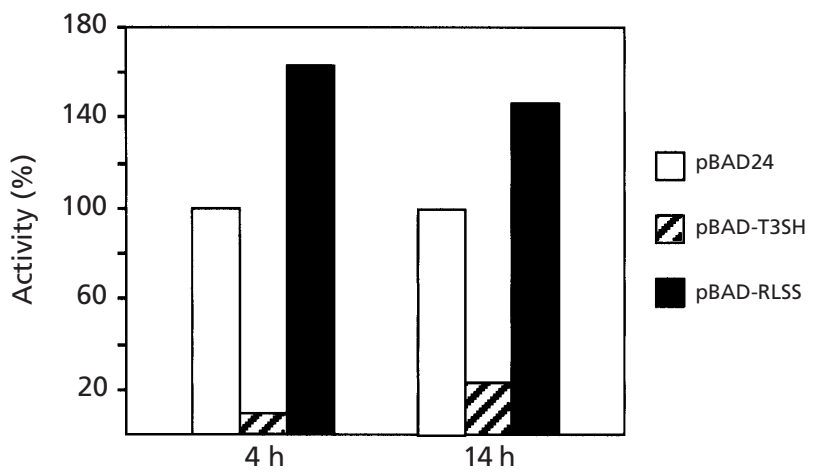

Fig. 4. In vivo manipulation of SAM levels influences Al-2 production: expression of T3SH, a SAM hydrolase, drastically reduces Al-2 levels in E. coli MG1655, whereas expression of RLSS, a SAM synthetase, increases Al-2 activity. Samples were taken after $4 \mathrm{~h}$ from cultures grown in the absence of glucose $\left(\mathrm{OD}_{600}\right.$ approximately $\left.1 \cdot 2\right)$ and after $14 \mathrm{~h}\left(\mathrm{OD}_{600}\right.$ approximately 3.6) from cultures grown in the presence of $10 \mathrm{mM}$ glucose. Expression of T3SH and RLSS was induced by the addition of $10 \mathrm{mM}$ L-arabinose $1 \mathrm{~h}$ after inoculation. Al-2 activities observed with the control (pBAD24 vector only), were defined as $100 \%$. This corresponded to a 300 -fold and 790 -fold induction of bioluminescence in the $V$. harveyi bioassay for the $4 \mathrm{~h}$ and $14 \mathrm{~h}$ sample, respectively. Al-2 activities for a single experiment are shown, although the experiment was repeated three times with similar results. Replicate assays agreed within $18 \%$.

Table 4. Inactivation of Al-2 activity by Ps. aeruginosa In vitro-synthesized $\mathrm{AI}-2$ in $50 \mathrm{mM}$ Tris/ $\mathrm{HCl}$ buffer, $\mathrm{pH} 7 \cdot 8$, was incubated with LB medium or cell suspensions for $2 \mathrm{~h}$. The remaining AI-2 activities for a single experiment are shown, although the experiment was repeated three times with similar results and replicate assays agreed within $20 \%$. AI-2 activity is compared with the background activity observed for the control $(50 \mathrm{mM}$ Tris/ $\mathrm{HCl}$ buffer, $\mathrm{pH} 7 \cdot 8$, incubated with LB medium).

\begin{tabular}{|lc|}
\hline Incubation mixture & $\begin{array}{c}\text { AI-2 activity } \\
\text { (fold induction) }\end{array}$ \\
\hline LB medium/AI-2 & 570 \\
E. coli $\mathrm{DH} 5 \alpha / \mathrm{AI}-2$ & 610 \\
E. coli $\mathrm{DH} 5 \alpha /$ Tris buffer & 2 \\
Ps. aeruginosa/AI-2 & 3 \\
Heat-inactivated Ps. aeruginosa/AI-2 & 590 \\
Ps. aeruginosa/Tris buffer & 2 \\
\hline
\end{tabular}

medium prior to incubation with in vitro-synthesized AI-2. Within $2 \mathrm{~h}$, washed cells of Ps. aeruginosa were capable of completely removing AI-2 activity (Table 4). Similarly, loss of activity was observed when AI-2 was added to growing cultures of Ps. aeruginosa (data not shown). However, the loss of AI-2 activity was not observed following incubation with heat-inactivated $P s$. aeruginosa cells, E. coli DH5 $\alpha$, or fresh culture medium. 


\section{DISCUSSION}

In this paper we have identified the pathway of AI-2 synthesis. LuxS is the sole requirement for the production of AI-2 activity and homocysteine from RH in vitro. We have demonstrated that the LuxS proteins of E. coli MG1655, N. meningitidis, Por. gingivalis and Staph. aureus catalyse identical reactions. We propose that LuxS is identical to the RH-cleavage enzyme identified first in E. coli by Duerre \& Miller (1966) and Miller \& Duerre (1968), which catalyses the conversion of $\mathrm{RH}$ to homocysteine and a reactive compound, identified as 4,5-dihydroxy-2,3,-pentanedione (Duerre et al., 1971). During the preparation of this manuscript Schauder et al. (2001) reported similar findings using the LuxS proteins of E. coli, V. harveyi, V. cholerae and Enterococcus faecalis and suggested that this pathway is used by bacteria to produce AI-2, a compound which may have a role in interspecies signalling. However, Schauder et al. (2001) were unable to elucidate the chemical structure of the product formed from 4,5dihydroxy-2,3-pentanedione which exhibits AI-2 activity. 4,5-Dihydroxy-2,3-pentanedione is not stable in aqueous solutions and is known to form furanone derivatives via cyclization and dehydration (Nedvidek et al., 1992; Blank \& Fay, 1996; for a review see Slaughter, 1999). We have demonstrated that the furanone MHF is formed in vitro using $\mathrm{RH}$ as a substrate and one of three different LuxS homologues derived from both Gramnegative and Gram-positive bacteria. Furthermore, MHF and a structurally related furanone, DMHF, were found to possess AI-2 activity. Schauder et al. (2001) have also demonstrated that furanones, including MHF, DMHF and 4-hydroxy-2-ethyl-5-methyl-3(2H)furanone (EMHF), exhibit AI-2 activity in the V. harveyi bioassay. Taken together, these results strongly suggest that AI-2 has a $3(2 H)$-furanone structure. The results presented in this study indicate that MHF is the main product formed from 4,5-dihydroxy-2,3-pentanedione. However, it is not yet clear whether the formation of MHF occurs spontaneously or is catalysed by the LuxS protein.

These findings raised the question as to whether MHF is AI-2. Although MHF appears to be the major product formed from the ribose moiety of $\mathrm{RH}$, synthetic MHF showed half-maximal activation in the $V$. harveyi bioassay only at the relatively high concentration of approximately $1 \mathrm{mM}$. In contrast, half-maximal activation was observed with only $1-3 \mu \mathrm{M}$ of the in vitrosynthesized AI-2, suggesting that this compound is different from MHF. Although we could not identify any substantial concentration of other furanones, MHF may not represent the only product formed from 4,5dihydroxy-2,3-pentanedione in vivo or in our in vitro system. Also, MHF itself is unstable under certain conditions (Whitfield \& Mottram, 1999, 2001) and may have formed additional compounds. The calculation of $\mathrm{AI}-2$ concentrations obtained in vitro is based on the amount of homocysteine produced and assumes a 1:1 ratio between homocysteine and AI-2. However, the true AI-2 concentrations may have been much lower and therefore not detected by GC-MS analysis. Incubation of synthetic MHF under the conditions used for in vitro synthesis of AI-2 did not increase the activity in the bioassay, suggesting that AI-2 is not a degradation product of MHF. Thus, our data suggest that AI-2 is either a minor (but highly active) side product formed from 4,5-dihydroxy-2,3-pentanedione, or a precursor in MHF formation. We are currently optimizing the in vitro production of larger quantities of AI-2 to establish unequivocally its chemical nature.

In contrast to our study, Schauder et al. (2001) reported that MHF concentrations of approximately $100 \mu \mathrm{M}$ were required for half-maximal activation in the $V$. harveyi bioassay, whereas AI-2 was active at a 1000-10000-fold lower concentration (10-100 nM). This could be the result of a discrepancy in data interpretation. The concentrations stated by Schauder $e t$ al. (2001) clearly coincide with the midpoint of graphs representing bioassay activity as a function of AI-2 or MHF concentration. However, the respective activity data have been presented using a logarithmic scale. Therefore, the midpoint of these graphs does not represent half-maximal activity, but a much lower value.

Whether AI-2 is a furanone or not, direct evidence for $\mathrm{AI}-2$ as a quorum-sensing signal molecule has only been obtained for V. harveyi (Bassler et al., 1994). The main function of the LuxS enzyme is clearly a metabolic one. All living organisms, with the possible exception of a few bacterial pathogens, produce SAM, a central metabolite, which functions as the major methyl donor. SAH is the co-product of SAM-dependent methyltransferase reactions (Fig. 1), which methylate DNA and RNA, as well as certain metabolites and proteins. The subsequent conversion of SAH is important, as SAH is a potent feedback inhibitor of the SAM-dependent methyltransferases (Gordon et al., 1987). Furthermore, it is advantageous to recycle the 'building blocks' of SAH. Eukaryotes and a number of bacteria remove SAH in a single step, catalysed by the SAH hydrolase, producing adenosine and homocysteine (Walker \& Duerre, 1975; Fig. 1). Other bacteria employ MTA/SAH'ase and the RH cleavage enzyme (LuxS) for the conversion of SAH to homocysteine (Walker \& Duerre, 1975; Shimizu et al., 1984). The importance of these reactions is demonstrated by the fact that the genomes of nearly all organisms analysed to date contain homologues for one of the two pathways. Even more remarkable is the fact that to date there is not a single example where bacteria contain both a SAH hydrolase and a LuxS protein (Fig. 5). This further supports the idea that LuxS represents the RH cleavage enzyme and fulfils primarily a metabolic function, together with MTA/SAH'ase, which is analogous to the SAH hydrolase reaction.

The metabolic flux from methionine to SAM, SAH, and finally homocysteine (Fig. 1) appears to be tightly controlled as, for instance, very low concentrations of SAM result in a cell division defect in E. coli (Newman et al., 1998). The amount of SAH produced correlates with the number of SAM-dependent methylations car- 
Organism

Eukarya

Archaea

\section{Bacteria}

$\alpha$-proteobacteria:

$\beta$-proteobacteria:

$\gamma$-proteobacteria:

Aquificales:

Chlamydiales:

Cyanobacteria:

Thermotogales:

Spirochaetales:

Cytophagales:

Deinococcus group: Deinococcus

Firmicutes: Arthrobacter

Bacillus

Clostridium

Nocardia

Nonomuraea

Micrococcus

Mycobacterium

Micromonospora

Mycoplasma

Staphylococcus

Streptococcus

Streptomyces

Streptosporangium

Ureaplasma

\section{SAH \\ MTA/ \\ RH-cleavage \\ hydrolase \\ SAH'ase \\ enzyme/LuxS}
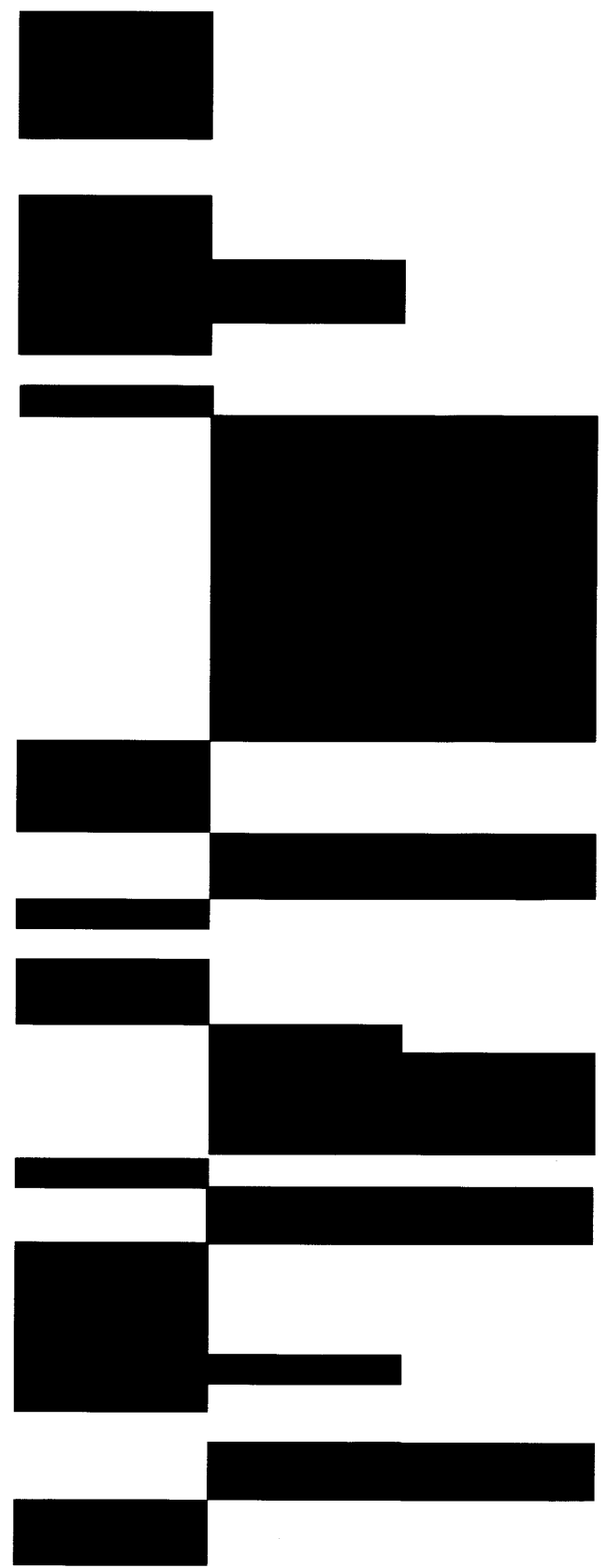

Fig. 5. Distribution of SAH-degrading pathways in various bacteria. The figure is based on biochemical evidence (Walker \& Duerre, 1975; Shimizu et al., 1984) and the presence of putative homologues identified by genome analysis. Only completed genomes have been considered. For gapped BLAST alignments, the LuxS, MTA/SAH'ase and SAH hydrolase proteins of V. harveyi, E. coli and Rhodobacter capsulatus, respectively, have been used. Only hits with an 'expect value' $(E)$ of lower than $10^{-12}$ have been considered. Positive results are marked with black boxes. For clarity, only the genera are given for the following species: Acinetobacter calcoaceticus, Agrobacterium tumefaciens, Alcaligenes faecalis, Aquifex aeolicus, Arthrobacter globiformis, Bacillus cereus, Bacillus halodurans, Bacillus subtilis, Borrelia burgdorferi, Campylobacter jejuni, Caulobacter crescentus, Chlamydia muridarum, Chlamydia pneumoniae, Chlamydia trachomatis, Citrobacter freundii, Citrobacter intermedius, Clostridium acetobutylicum, Deinococcus radiodurans, Enterobacter aerogenes, Escherichia coli, Haemophilus influenzae, Helicobacter pylori, Mesorhizobium loti, Micrococcus luteus, Micromonospora faeni, Mycobacterium leprae, Mycobacterium tuberculosis, Mycobacterium avium, Mycoplasma genitalium, Mycoplasma pneumoniae, Mycoplasma pulmonis, Neisseria meningitidis, Nocardia asteroides, Nonomuraea angiospora (formerly Micropolyspora angiospora), Pasteurella multocida, Porphyromonas gingivalis, Proteus inconstans, Pseudomonas aeruginosa, Pseudomonas putida, Rickettsia prowazekii, Rhodobacter capsulatus, Rhodobacter 
ried out in the cell. Thus, it can be predicted that lowering the cellular concentration of SAM will lead to a decrease in SAH levels and hence AI-2 production. We found that this is indeed the case by expressing the SAMhydrolysing T3SH enzyme in E. coli MG1655. Furthermore, overexpression of the SAM synthetase RLSS increased AI-2 levels moderately. It is possible that increasing SAM levels did not result in a substantial increase in SAM-dependent methylase reactions, and thus $\mathrm{SAH}$, due to the conditions employed in this study.

Our findings raise the interesting question why some bacteria employ two enzymic steps to achieve what other bacteria and eukaryotes can accomplish in a single step. It has been suggested that one of the reasons for employing two steps is that it leads to the production of the signal molecule AI-2 (Schauder et al., 2001). However, an alternative explanation is that one of the products formed via the MTA/SAH'ase and LuxS reactions may fulfil an additional function not connected with signalling. It is, however, remarkable that the synthesis of AI-2, which is clearly used as a signal molecule by $V$. harveyi, relies on the degradation of a metabolite, whereas other signal molecules, for instance the $\mathrm{N}$-acylhomoserine lactones, are synthesized by dedicated synthases.

In a number of publications authors have claimed to present evidence for AI-2-based quorum sensing after detecting AI-2 activity in culture supernatants or discovering phenotypic differences between wild-type strains and luxS mutants (Surette \& Bassler, 1998; Sperandio et al., 1999, 2001; Forsyth \& Cover, 2000; Joyce et al., 2000; Burgess et al., 2002; Day \& Maurelli, 2001; Lyon et al., 2001). Their work had been motivated by initial studies showing that the production of AI-2 is luxS dependent (Surette et al., 1999), and because it had been suggested that AI-2 may represent an universal signal molecule, used for intra- as well as interspecies communication (Bassler, 1999). However, a second, metabolic, function of the LuxS protein had not been taken into account, and therefore few attempts have been made to restore wild-type phenotypes in $\operatorname{lu} x S$ mutants through the addition of exogenous AI-2. Using a DNA-microarray-based approach, Sperandio et al. (2001) identified more than 400 genes in E. coli O157: H7 which showed significant changes in expression in a luxS mutant. They concluded that AI-2-based quorum sensing is a global regulatory mechanism in this organism, although only two phenotypes (growth rate and halo size on motility plates) were analysed for restoration after the addition of conditioned medium from wildtype cultures. However, with the expression pattern for so many genes changed, conditioned medium of wildtype and luxS mutant is very likely to differ not only with regard to AI-2 but also in many other respects, e.g. the concentration of various fermentation products and secondary metabolites. Therefore, restoration of wild-type characteristics could depend on compounds different from AI-2, but also changed in the luxS mutant due to the disruption of the metabolic cycle described in Fig. 1. The same is true for the E. coli DNA microarray studies performed by DeLisa et al. (2001b) and the virB expression studies of Day \& Maurelli (2001) in Sh. flexneri. DeLisa et al. (2001b) identified significant transcriptional changes in 242 genes by comparing expression profiles of E. coli luxS mutants incubated for $20 \mathrm{~min}$ in the presence of conditioned medium from either wild-type or $\operatorname{luxS}$ mutant. Although the conditioned medium was derived from cultures grown to an $\mathrm{OD}_{600}$ of 3 , but added to cells derived from cultures grown to an $\mathrm{OD}_{600}$ of $1 \cdot 0$, no data have been presented to demonstrate that the changes observed were specific for the $\operatorname{luxS}$ mutant and AI-2 and did not occur with wild-type cells. We therefore conclude that convincing evidence for AI-2-based quorum sensing in the organisms mentioned above has not yet been presented, and that many phenotypes linked to $\operatorname{luxS}$ may have their origin in the disruption of the metabolic cycle outlined in Fig. 1. Furthermore, with the exception of other Vibrio species, genome analysis reveals no evidence for a signal-transduction cascade similar to the one described for the $V$. harveyi quorum-sensing system. Thus, these results again raise the question whether AI-2 functions as a signal molecule for the majority of species or whether it is just a 'by-product' of the LuxS reaction.

Despite the evidence for the significance of SAHdegrading pathways, not all $\operatorname{luxS}$ mutants show significant phenotypic changes under laboratory conditions (Forsyth \& Cover, 2000; Joyce et al., 2000). However, the presence of these pathways in nearly all organisms as well as the high degree of conservation within the SAH hydrolase, MTA/SAH'ase and LuxS protein families indicates the importance of these metabolic conversions in the natural environment. The inactivation of $\operatorname{lu} x S$ is likely to manifest itself in various phenotypes, depending on the metabolic capabilities of the species studied and the growth conditions used. For instance, methionineauxotrophic bacteria will be expected to differ from prototrophic species, and the artificial growth conditions used in the laboratory may or may not reveal a reduction in fitness. This view is supported by the observation that a N. meningitidis luxS mutant, which shows no obvious phenotype under laboratory conditions, is clearly attenuated in the infant rat model, even in mixed-inoculum experiments, where AI-2 produced by the wild-type is expected to overcome a potential quorum-sensing defect (Winzer et al., 2002). Thus, the attenuation observed for the N. meningitidis luxS mutant is most likely the result of metabolic problems

sphaeroides, Roseobacter denitrificans, Salmonella enterica serovar Typhimurium, Sinorhizobium meliloti, Staphylococcus aureus, Streptococcus pyogenes, Streptococcus pneumoniae, Streptomyces hygroscopicus, Streptomyces kentuckensis (formerly Streptoverticillium kentuckense), Streptomyces yerevanensis (formerly Microellobospora violacea), Streptosporangium roseum, Synechocystis sp., Thermotoga maritima, Treponema pallidum, Ureaplasma urealyticum, Vibrio cholerae, Xylella fastidiosa. 
arising from the incapability to degrade $\mathrm{RH}$, rather than a quorum-sensing defect. With the discovery of the AI-2 biosynthesis pathway and the availability of in vitro-synthesized AI-2, we will now be able to establish whether any phenotypes observed with a luxS mutant are caused by a metabolic or a signalling defect. The latter should be overcome by the addition of exogenous AI-2.

E. coli and Sal. typhimurium have both been reported to degrade AI-2 activity in the absence of glucose (Surette \& Bassler, 1998, 1999), and the removal of AI-2 activity has also been described for Strep. pyogenes and $N$. meningitidis (Lyon et al., 2001; Winzer et al., 2002). Thus, it appears that AI-2 is released during exponential growth, and degraded, depending on bacterial species and culture conditions, during late exponential, transition to stationary or stationary phase. But why should bacteria remove AI-2 molecules? From a signalling perspective, such degradation could be part of a 'switchoff' mechanism, which resets the system. From a metabolic perspective, it would be advantageous to avoid the loss of 'expensive' compounds, which could be channelled back into the central metabolism. With regard to the LuxS reaction, assuming a 1:1 ratio between homocysteine and AI-2 production and a complete release of AI-2, bacteria would lose one 'ribose-equivalent' unit per methyl-group transfer. This would be a high price to pay. Thus, in the absence of glucose, E. coli and Sal. typhimurium may make use of AI-2 (or MHF, the final product), inducing a system which is otherwise controlled in a fashion resembling catabolite repression. Interestingly, MHF and DMHF have both been identified as DNA-damaging agents, and MHF is also mutagenic to Sal. typhimurium (Hiramoto et al., 1996; Yamashita et al., 1998), which could explain the exclusion of AI-2 from the cells during exponential growth. At a later stage, controlled uptake and degradation of AI-2 (and MHF) may prevent build-up of toxic intracellular levels. Bacteria such as Ps. aeruginosa, which do not produce AI-2 but are capable of degrading it, may also metabolize the compound and use it as a carbon or energy source. However, degradation by these bacteria could also serve to disrupt communication between other bacteria, similar to the degradation of $\mathrm{N}$-acylhomoserine lactones by Variovorax paradoxus (Leadbetter \& Greenberg, 2000) or Bacillus sp. 240B1 (Dong et. al. 2000).

Where used for interspecies communication, the AI-2 system could only detect the 'quorum' of its producers. But such a system is difficult to envisage, as different species may produce the molecule at different rates while others may degrade the molecule at the same time. Furthermore, furanones present in the environment may interfere with such a system. DMHF, for instance, has been discovered in fruits like tomatoes, strawberries and pineapples, as well as in yeast fermentation products, and is also produced by lactic acid bacteria (Slaughter, 1999; Hayashida et al., 2001). Thus it appears that the use of AI-2 molecules for intra- or interspecies com- munication will only make sense in certain habitats, such as that occupied by $V$. harveyi.

In summary, we propose that in many species AI-2 does not function as a signal molecule but is simply a metabolite, which is excreted early during growth but can be taken up and metabolized at a later stage. Some bacteria, notably $V$. harveyi and possibly related species, may have evolved signalling systems which use AI-2 as a 'quorum-sensing molecule'. Competing bacteria, even those which do not produce AI-2, may co-metabolize the molecule and use it as a source of carbon.

\section{ACKNOWLEDGEMENTS}

We would like to thank Mavis Daykin for HPLC analysis, and Alan Cockayne, Tom Baldwin and Helen Withers for stimulating discussions. We are grateful to Leona D. Samson (Massachusetts Institute of Technology) for supplying plasmids pBAD-RLSS and pBAD-T3SH. Givaudan generously provided a free sample of synthetic MHF. The work presented was supported by grants from the Medical Research Council UK, Biotechnology and Biological Sciences Research Council (BBSRC) UK, the British Society for Antimicrobial Therapy and by a BBSRC CASE studentship (N.B.) in partnership with SmithKline Beecham Pharmaceuticals.

\section{REFERENCES}

Bassler, B. L. (1999). How bacteria talk to each other: regulation of gene expression by quorum sensing. Curr Opin Microbiol 2, 582-587.

Bassler, B. L., Wright, M. \& Silverman, M. R. (1994). Multiple signalling systems controlling expression of luminescence in Vibrio harveyi: sequence and function of genes encoding a second sensory pathway. Mol Microbiol 13, 273-286.

Bassler, B. L., Greenberg, E. P. \& Stevens, A. M. (1997). Crossspecies induction of luminescence in the quorum sensing bacterium Vibrio harveyi. J Bacteriol 179, 4043-4045.

Blank, I. \& Fay, L. B. (1996). Formation of 4-hydroxy-2,5-dimethyl$3(2 H)$-furanone and 4-hydroxy-2(or 5)-5(or 2) methyl-3(2H)furanone through Maillard reaction based on pentose sugars. $J$ Agric Food Chem 44, 531-536.

Burgess, N., Kirke, D., Williams, P., Winzer, K., Hardie, K. R., Meyers, N. L., Aduse-Opoku, J., Curtis, M. A. \& Cámara, M. (2002). LuxS-dependent quorum sensing in Porphyromonas gingivalis modulates protease and haemagglutinin activities but is not essential for virulence. Microbiology 148, 763-772.

Chung, W. O., Park, Y., Lamont, R. J., McNab, R., Barbieri, B. \& Demuth, D. R. (2001). Signaling system in Porphyromonas gingivalis based on a LuxS protein. J Bacteriol 183, 3903-3909.

Cornell, K. A. \& Riscoe, M. K. (1998). Cloning and expression of Escherichia coli 5'-methylthioadenosine/S-adenosylhomocysteine nucleosidase: identification of the $p f s$ gene product. Biochim Biophys Acta 1396, 8-14.

Day, W. A. \& Maurelli, A. T. (2001). Shigella flexneri LuxS quorum sensing system modulates $\operatorname{vir} B$ expression but is not essential for virulence. Infect Immun 69, 15-23.

DeLisa, M. P., Valdes, J. J. \& Bentley, W. E. (2001a). Mapping stress-induced changes in autoinducer AI-2 production in chemostat-cultivated Escherichia coli K-12. J Bacteriol 183, 2918-2928. 
DeLisa, M. P., Wu, C. F., Wang, L., Valdes, J. J. \& Bentley, W. E. (2001b). DNA microarray-based identification of genes controlled by autoinducer 2-stimulated quorum sensing in Escherichia coli. J Bacteriol 183, 5239-5247.

Dong, Y. H., Xu, J. L., Li, X. Z. \& Zhang, L. H. (2000). AiiA, an enzyme that inactivates the acylhomoserine lactone quorumsensing signal and attenuates the virulence of Erwinia carotovora. Proc Natl Acad Sci US A 97, 3526-3531.

Duerre, J. A. (1962). A hydrolytic nucleosidase acting on $S$ adenosylhomocysteine and on $5^{\prime}$-methylthioadenosine. $\mathrm{J} \mathrm{Biol}$ Chem 237, 3737-3741.

Duerre, J. A. \& Miller, C. H. (1966). Cleavage of S-ribosyl-Lhomocysteine by extracts from Escherichia coli. J Bacteriol 91, 1210-1217.

Duerre, J. A., Baker, D. J. \& Salisbury, L. (1971). Structure elucidation of a carbohydrate derived from $S$-ribosylhomocysteine by enzymatic cleavage. Fed Proc 30, 88.

Farine, J.-P., Le Quere, J.-L., Duffy, J., Semon, E. \& Brossut, R. (1993). 4-Hydroxy-5-methyl-3(2H)-furanone and 4-hydroxy-2,5dimethyl-3(2H)-furanone, two components of the male sex pheromone of Eurycotis flordana (Walker) (Insecta, Blattidae, Polyzosteriinae). Biosci Biotechnol Biochem 57, 2026-2030.

Forsyth, M. H. \& Cover, T. L. (2000). Intercellular communication in Helicobacter pylori: luxS is essential for the production of an extracellular signaling molecule. Infect Immun 68, 3193-3199.

Gardiner, S. M., Chhabra, S. R., Harty, C., Williams, P., Pritchard, D. I., Bycroft, B. W. \& Bennett, T. (2001). Haemodynamic effects of the bacterial quorum sensing signal molecule, N-(3oxododecanoyl)-L-homoserine lactone, in conscious, normal and endotoxaemic rats. Br J Pharmacol 133, 1047-1054.

Gordon, R. K., Miura, G. A., Alonso, T. \& Chiang, P. K. (1987). $S$-Adenosylmethionine and its sulfur metabolites. Methods Enzymol 143, 191-195.

Greenberg, E. P. (1999). Quorum sensing in Gram-negative bacteria: acylhomoserine lactone signalling and cell-cell communication. In Microbial Signalling and Communication (Society for General Microbiology Symposium no. 57), pp. 71-84. Edited by R. England, G. Hobbs, N. Bainton \& D. McL. Roberts. Cambridge: Cambridge University Press.

Greenberg, E. P., Hastings, J. W. \& Ulitzer, S. (1979). Induction of luciferase sunthesis in Beneckea harveyi by other marine bacteria. Arch Microbiol 120, 87-91.

Greene, R. C. (1996). Biosynthesis of methionine. In Escherichia coli and Salmonella: Cellular and Molecular Biology, 2nd edn, vol. 1, pp. 542-560. Edited by F. C. Neidhardt and others. Washington, DC: American Society for Microbiology.

Guzman, L.-M., Belin, D., Carson, M. J. \& Beckwith, J. (1995). Tight regulation, modulation, and high level expression by vectors containing the arabinose pBAD promoter. J Bacteriol $\mathbf{1 7 7}$, 4121-4130.

Hayashida, Y., Hatano, M., Tamura, Y., Kakimoto, M., Nishimura, K., Igoshi, K., Kobayashi, H. \& Kuriyama, H. (2001). 4-Hydroxy2,5-dimethyl-3(2H)-furanone (HDMF) production in simple media by lactic acid bacterium, Lactococcus lactis subsp. cremoris IFO 3427. J Biosci Bioeng 91, 97-99.

Hiramoto, K., Sekiguchi, K., Ayuha, K., Aso-o, R., Morya, N., Kato, T. \& Kikugawa, K. (1996). DNA breaking activity and mutagenicity of soy sauce: characterization of the active components and identification of 4-hydroxy-5-methyl-3(2H)-furanone. Mutat Res 359, 119-132.

Jiang, Y., Camara, M., Chhabra, S. R., Hardie, K. R., Bycroft, B. W., Lazdunski, A., Salmond, G. P., Stewart, G. S. \& Williams, P. (1998).
In vitro biosynthesis of the Pseudomonas aeruginosa quorumsensing signal molecule N-butanoyl-L-homoserine lactone. Mol Microbiol 28, 193-203.

Joyce, E. A., Bassler, B. L. \& Wright, A. (2000). Evidence for a signalling system in Helicobacter pylori: detection of a luxSencoded autoinducer. J Bacteriol 182, 3638-3643.

Kleerebezem, M., Quadri, L. E. N., Kuipers, O. P. \& de Vos, W. M. (1997). Quorum sensing by peptide pheromones and two component signal transduction systems in Gram-positive bacteria. Mol Microbiol 24, 895-904.

Lazazzera, B. A. \& Grossman, A. D. (1998). The ins and outs of peptide signalling. Trends Microbiol 6, 288-294.

Leadbetter, J. R. \& Greenberg, E. P. (2000). Metabolism of acylhomoserine lactone quorum-sensing signals by Variovorax paradoxus. J Bacteriol 182, 6921-6926.

Lyon, W. R., Madden, J. C., Levin, J. C., Stein, J. L. \& Caparon, M. G. (2001). Mutation of $l u x S$ affects growth and virulence factor expression in Streptococcus pyogenes. Mol Microbiol 42, $145-157$.

Miller, C. H. \& Duerre, J. A. (1968). S-Ribosylhomocysteine cleavage enzyme from Escherichia coli. J Biol Chem 243, 92-97.

Moré, M. I., Finger, L. D., Stryker, J. L., Fuqua, C., Eberhard, A. \& Winans, S. C. (1996). Enzymatic synthesis of a quorum-sensing autoinducer through the use of defined substrates. Science 272, $1655-1658$.

Nedvidek, W., Ledl, F. \& Fischer, P. (1992). Detection of 5hydroxymethyl-2-methyl-3(2H)-furanone and of $\alpha$-dicarbonyl compounds in reaction mixtures of hexoses and pentoses with different amines. Z Lebensm-Unters-Forsch 194, 222-228.

Newman, E. B., Budman, L. I., Chan, E. C., Greene, R. C., Lin, R. T., Woldringh, C. L. \& D'Ari, R. (1998). Lack of $S$-adenosylmethionine results in a cell divison defect in Escherichia coli. J Bacteriol 180, 3614-3619.

Novick, R. P. (1999). Regulation of pathogenicity in Staphylococcus aureus by a peptide-based density-sensing system. In Cell-Cell Signaling in Bacteria, pp. 129-146. Edited by G. M. Dunny \& S. C. Winans. Washington, DC: American Society for Microbiology

Novick, R. P. \& Muir, W. M. (1999). Virulence gene regulation by peptides in staphylococci and other Gram-positive bacteria. Cur Opin Microbiol 2, 40-45.

Posnick, L. M. \& Samson, L. D. (1999). Influence of S-adenosylmethionine pool size on spontaneous mutation, dam methylation, and cell growth. J Bacteriol 181, 6756-6762.

Sambrook, J., Fritsch, E. F. \& Maniatis, T. (1989). Molecular Cloning: a Laboratory Manual, 2nd edn. Cold Spring Harbor, NY : Cold Spring Harbor Laboratory.

Schauder, S., Shokat, K., Surette, M. G. \& Bassler, B. L. (2001). The LuxS family of bacterial autoinducers: biosynthesis of a novel quorum sensing signal molecule. Mol Microbiol 41, 463-476.

Schweizer, H. P. (1991). Escherichia-Pseudomonas shuttle vectors derived from pUC18/19. Gene 97, 109-121.

Shimizu, S., Shiozaki, S., Ohshiro, T. \& Yamada, H. (1984). Occurrence of $S$-adenosylhomocysteine in prokaryote cells. Characterization of the enzyme from Alcaligenes faecalis and role of the enzyme in the activated methyl cycle. Eur J Biochem 141, 385-392.

Slaughter, J. C. (1999). The naturally occuring furanones: formation and function from pheromone to food. Biol Rev Camb Philos Soc 74, 259-276.

Smith, A. W. \& Iglewski, B. H. (1989). Transformation of 
Pseudomonas aeruginosa by electroporation. Nucleic Acids Res 17, 105-109.

Sperandio, V., Mellies, J. L. , Nguyen, W. , Shin, S. \& Kaper, J. B. (1999). Quorum sensing controls expression of the type III secretion gene transcription and protein secretion in enterohemorrhagic and enteropathogenic Escherichia coli. Proc Natl Acad Sci U S A 96, 15196-15201.

Sperandio, V., Torres, A. G., Giron, J. A. \& Kaper, J. B. (2001). Quorum sensing is a global regulatory mechanism in enterohemorrhagic Escherichia coli O157:H7. J Bacteriol 183, 5187-5197.

Surette, M. G. \& Bassler, B. L. (1998). Quorum sensing in Escherichia coli and Salmonella typhimurium. Proc Natl Acad Sci U S A 95, 7046-7050.

Surette, M. G. \& Bassler, B. L. (1999). Regulation of autoinducer production in Salmonella typhimurium. Mol Microbiol 31, 585-595.

Surette, M. G., Miller, M. B. \& Bassler, B. L. (1999). Quorum sensing in Escherichia coli, Salmonella typhimurium, and Vibrio harveyi: a new family of genes responsible for autoinducer production. Proc Natl Acad Sci U S A 96, 1639-1644.

Telford, G., Wheeler, D., Williams, P., Tomkins, P. T., Appleby, P., Sewell, H., Stewart, G. S. A. B., Bycroft, B. W. \& Pritchard, D. I. (1998). The Pseudomonas aeruginosa quorum sensing signal molecule, $\mathrm{N}$-(3-oxododecanoyl)-L-homoserine lactone, has immunomodulatory activity. Infect Immun 66, 36-42.

Walker, R. D. \& Duerre, J. A. (1975). S-Adenosylmethionine metabolism in various species. Can J Biochem 53, 312-319.
Whitfield, F. B. \& Mottram, D. S. (1999). Investigation of the reaction between 4-hydroxy-5-methyl-3(2H)-furanone and cysteine or hydrogen sulfide at $\mathrm{pH} 4$ 4. J Agric Food Chem 47, $1626-1634$

Whitfield, F. B. \& Mottram, D. S. (2001). Heterocyclic volatiles formed by heating cysteine or hydrogen sulfide with 4-hydroxy5-methyl-3(2H)-furanone at $\mathrm{pH}$ 6.5. J Agric Food Chem 49, 816-822.

Williams, P., Camara, M., Hardman, A. \& 7 other authors (2000). Quorum sensing and the population dependent control of virulence. Philos Trans R Soc Lond B Biol Sci 355, 667-680.

Winzer, K., Sun, Y.-H., Green, A., Delory, M., Blackley, D., Hardie, K. R., Baldwin, T. J. \& Tang, C. (2002). The role of Neisseria meningitidis luxS in cell-to-cell signaling and bacteraemia. Infect Immun (in press).

Withers, H., Swift, S. \& Williams, P. (2001). Quorum sensing as an integral component of gene regulatory networks in Gramnegative bacteria. Curr Opin Microbiol 4, 186-193.

Yamashita, N., Murata, M., Inoue, S., Hiraki, Y., Yoshiaga, T. \& Kawanishi, S. (1998). Superoxide formation and DNA damage induced by a fragrant furanone in the presence of copper (II). Mutat Res 397, 191-201.

Yanisch-Perron, C., Vieira, J. \& Messing, J. (1985). Improved M13 phage cloning vectors and host strains: nucleotide sequences of the M13mp18 and pUC19 vectors. Gene 33, 103-119.

Received 3 September 2001; revised 21 November 2001; accepted 23 November 2001. 